\title{
Diyarbakır ili buğday tarlalarında bulunan yabancı otların belirlenmesi
}

\author{
Firat PALA $^{1} \quad$ Hüsrev MENNAN ${ }^{2}$
}

\author{
ABSTRACT \\ Determination of weed species in wheat fields of Diyarbakir province
}

This study was carried out as a survey to determine weed species, their observation frequencies and densities in wheat fields of seventeen districts of Diyarbakır province during 2016-2017. For this purpose, field observations were made in total 106 location and the weed species and their frequency and densities were recorded. As a result of the observations; 107 weed species belonging to 26 families, 1 seedlees, 19 monocotyledons, 87 dicotyledons were detected. Families of Asteraceae, Poaceae, Brassicaceae, Apiaceae and Fabaceae, which are the most dominant in the fields and containing $2 / 3$ of all species have been found in survey. Avena fatua L., Sinapis arvensis L., Ranunculus arvensis L., Galium aparine L. ve Cirsium arvense (L.) Scop. were identified as the most common species respectively, and their ratios are 87, 78, 72, 62 and 58\%. According to density Avena fatua L. with 9.73 plant $\mathrm{m}^{-2}$ has received the first place. It was followed by Sinapis arvensis L., Galium aparine L., Papaver rhoeas L., Cirsium arvense (L.) Scop. with the numbers of 8.83, 5.94, 2.62 ve 2.45 plant m2 respectively. Despite the decrease in frequency and density of weeds compared to past years, the results obtained have shown that effective weed management is not exercised.

Keywords: Wheat, weeds, survey, frequency, density

\section{ÖZ}

$\mathrm{Bu}$ çalışma, Diyarbakır ili buğday tarlalarında görülen yabancı otların yaygınlık ve yoğunluklarının belirlenmesi amacıyla 2016-2017 üretim döneminde buğday yetiştiriciliği yapılan 17 ilçede sürvey çalışmaları şeklinde yürütülmüştür. Bu amaçla toplam 106 tarlada arazi gözlemleri yapılmış, yabancı of türlerinin yaygınlıkları ve yoğunlukları belirlenmiştir.

Yapılan gözlemler sonucunda, 1 tohumsuz, 19 monokotiledon ve 87 dikotiledon olmak üzere 26 familyaya ait toplam 107 yabancı ot türü tespit edilmiştir. Sürvey alanında en yoğun olarak

\footnotetext{
${ }^{1}$ Siirt Üniversitesi, Ziraat Fakültesi, Bitki Koruma Bölümü, 56100, Merkez, Siirt

${ }^{2}$ Ondokuz Mayıs Üniversitesi, Ziraat Fakültesi, Bitki Koruma Bölümü, 55105, Atakum, Samsun Sorumlu yazar (Corresponding author) e-mail: firatpala@siirt.edu.tr Alınış (Received): 21.06.2017, Kabul ediliş (Accepted): 27.12.2017
} 
tespit edilen Asteraceae, Poaceae, Brassicaceae, Apiaceae ve Fabaceae familyalarının, tüm türlerin 2/3'ünü içerdiği görülmüştür. Rastlama sıklığı en yüksek yabancı otlar Avena fatua L., Sinapis arvensis L., Ranunculus arvensis L., Galium aparine L. ve Cirsium arvense (L.) Scop. ve oranları sırasılla \%87, 78, 72, 62 ve 58 olarak belirlenmiştir. Yoğunluğu en fazla olan yabancı otlar sirasiyla Avena fatua L., Sinapis arvensis L., Galium aparine L., Papaver rhoeas L., Cirsium arvense (L.) Scop. ve yoğunlukları sırasıyla 9.73, 8.83, 5.94, 2.62 ve 2.45 adet $\mathrm{m}^{2}$ olarak saptanmıştır. Yabancı otların yaygınlık ve yoğunluğu geçmiş yıllara göre azalmasına rağmen elde edilen sonuçlar etkili bir mücadele yapılamadığını göstermiştir.

Anahtar kelimeler: Buğday, yabancı ot, sürvey, rastlama sıklığı, yoğunluk

\section{GíRiş}

Buğday tarımı insan beslenmesindeki temel besinlerin ham maddesi olması açısından, diğer tarımsal ürünlere oranla ayrı bir önem taşımaktadır (AHDB 2017). Özellikle ülkemizde buğday ve buğdaydan yapılan gıda maddeleri tüketiminin birinci sırayı alması nedeniyle bu önem daha da artmaktadır. Geniş adaptasyon yeteneğine sahip buğday, dünyada üretimi (220 milyon ha alanda 713 milyon ton) en fazla yapılan tahıldır. Çin, Hindistan, Amerika, Rusya, Avustralya, Kanada, Ukrayna, Türkiye ve Kazakistan gibi ülkeler, buğday üretiminde dünyada ilk sıralarda yer almaktadır (FAO 2017). Türkiye 7 milyon ha ve 16 milyon ton ile \%2.4'lük bir paya sahiptir. Ülkemizde buğday en çok Konya, Diyarbakır ve Ankara illerinde üretilmektedir. Ülkesel buğday üretimimizin $\% 5$ 'lik bölümüne sahip olan Diyarbakır'da üretimi sınırlandıran faktörlerin başında yabancı otlar gelmektedir (Güncan 2014, TÜİK 2017).

Yabancı otlar, kültür bitkileri ile su, besin maddesi ve ışık açısından rekabete girerek verim ve kaliteyi doğrudan etkilemekle birlikte, buğdayda önemli bazı hastalık ve zararlı etmenlere de konukçuluk etmektedirler (Güncan 2014, Mennan ve Uygur 1994, Tepe 2014). Bu nedenle buğday üretim alanlarındaki yabancı otların bilinmesi ve bunlarla mücadele edilmesi kaçınılmazdır (Turk and Tawaha 2003). Etkili bir mücadele için sorun olan yabancı ot türlerinin, dağglımlarının, yoğunluklarının ve baskınlıklarının bilinmesi büyük önem arz etmektedir. Floradaki yabancı otların ortaya konması, alınacak tedbirler ve uygulanacak yöntemlerin belirlenmesi açısından da önemlidir (Shahzad et al. 2016).

Dünyada yapılan çalışmalarda buğday tarlalarında yabani yulaf, yabani hardal, tarla düğün çiçeği, dil kanatan, köygöçüren, kendi gelen mercimek, gelincik, papatya çobandeğneği, tarla sarmaşı̆̆ı, gökbaş ve pitrak gibi kışlık yabancı ot türlerinin baskın olduğu görülmektedir (Boz ve ark. 2000, Gökalp ve Üremiş 2015, Güncan 2014, Kadıoğlu 1989, Kaya ve Zengin 2000, Keshavarzi 2015, Kitiş ve Boz 2003, Kordali ve Zengin 2011, Kraehmer 2016, Özaslan 2011, Sirma ve Kadıŏlu 2010, Sizer ve Tepe 2016, Tursun 2002, Uygur ve ark. 1993). İklim farkları, yetiştiricilik teknikleri ve özellikle uygulanan yabancı ot kontrol yöntemleri tarım alanlarındaki yabanc1 ot kompozisyonunu değiştirebilmektedir (Kraehmer 2016). 
Diyarbakır ili sıcak ve kurak bir iklime sahip olması nedeniyle, bu ekolojik koşullara iyi uyum sağlamış olan yabancı otların buğday alanlarında sorun olması beklenen bir durumdur (Uludağ 1997). Önceki çalışmalar incelendiğinde, ilimiz buğday alanlarında 1966 ve 1992 yıllarında dil kanatan otunun yoğunluğunun 19.29 adet m$^{-}$ ${ }^{2}$ 'den 2.3 'e düştüğüne ve tarla düğün çiçeğinin ise 4.4 ve 1.6 adet $\mathrm{m}^{-2}$ düştügüne ilişkin bilgiler mevcuttur (Uludağ ve Katkat 1993, Zel 1974). Ancak yabancı otlar halen \%30 verim kaybına neden olmaktadır (Özer ve ark. 1998). Küresel ısınmanın, GAP kapsamında yapılan barajların ve uygulanan yabancı ot mücadele yöntemlerinin ilimiz buğday alanlarında yabancı ot florasında meydana getirdiği değişimlerin belirlenmesi entegre yabanc1 ot kontrol stratejilerinin geliştirilmesi için önemlidir.

Bu çalışmada Diyarbakır ili buğday ekim alanlarında görülen yabancı ot türleri, rastlama sıklıkları ve yoğunlukları araştırılmıştır.

\section{MATERYAL VE METOT}

Çalışmanın ana materyalini Diyarbakır ili buğday tarlalarında bulunan yabancı ot türleri oluşturmuştur. Bunun yanında sürveyler sırasında yabancı ot yoğunluklarını belirlemek üzere sistematik örnekleme yöntemine göre bir metrekarelik çerçeve kullanılmıştır (Odum 1971). Bitki türlerinin tespiti için de binoküler mikroskoptan yararlanılmıştır.

Sürvey çalışmaları Diyarbakır ilinde buğday üretiminin yapıldığı 17 ilçenin tamamında gerçekleştirilmiştir. Bu amaçla 2016-2017 vejetasyon dönemlerini kapsayacak şekilde toplam 106 tarlada sürveyler yapılmıştır. İlde en fazla üretim alanları dikkate alınarak oransal bir dağıtım yapılmıştır (Çizelge 1).

Çizelge 1. Diyarbakır ili buğday tarlalarında yabancı ot sürveyi yapılan ilçeler ve örnekleme sayıları

\begin{tabular}{lrc}
\hline İlçe Adı & Ekilen alan (da) & $\begin{array}{c}\text { Örnek } \\
\text { Sayısı }\end{array}$ \\
\hline Sur & 665.506 & 27 \\
Silvan & 505.118 & 20 \\
Bismil & 504.415 & 20 \\
Ergani & 229.502 & 9 \\
Dicle & 115.025 & 5 \\
Kocaköy & 104.461 & 4 \\
Lice & 83.471 & 3 \\
Bağlar & 82.045 & 3 \\
Kayapınar & 71.704 & 3 \\
Çınar & 60.757 & 2 \\
Kulp & 59.353 & 2 \\
Yenişehir & 58.768 & 2 \\
Çermik & 43.450 & 2
\end{tabular}


Çizelge 1. Devamı

\begin{tabular}{lcc}
\hline İlçe Adı & Ekilen alan $(\mathbf{d a})$ & $\begin{array}{c}\text { Örnek } \\
\text { Sayısı }\end{array}$ \\
\hline Eğil & 27.324 & 1 \\
Çüngüs & 14.850 & 1 \\
Hani & 10.570 & 1 \\
Hazro & 2.590 & 1 \\
\hline Toplam & $\mathbf{2 . 6 3 8 . 9 0 9}$ & $\mathbf{1 0 6}$ \\
\hline *Veriler TUiK (TÜiK 2017) kayıtlarından alınmıștır.
\end{tabular}

Sürveyler yabancı otların teşhislerinin kolayca yapılacağı dönemlerde (mart-mayıs aylarında) yapılmıştır. Örneklemenin yapıldığı tarlalarda her bir tarla arasında en az 3 km'lik mesafe olmasına özen gösterilmiştir. Örnekleme yapılan alanların aynı istikamette olsa dahi farklı lokasyon ve yöneylerde olmasına özen gösterilmiştir. Kenar tesirini ortadan kaldırmak için tarlaların en az $10 \mathrm{~m}$ içerisinden sayımlara başlanmıştır. Sürvey amacıyla girilen tarlalarda, alan büyüklügüne göre 5 dekara kadar olan tarlalarda 4, 5-10 dekar alanlarda 6, 10-20 dekar alanlarda 8, 20-50 dekarlık alanlarda 12 ve daha büyük alanlarda $16 \mathrm{kez} 1 \mathrm{~m}^{2}$ 'lik çerçeveler atılarak sayım yapılmıştır. Geniş yapraklı yabancı otlar tüm bitki olarak, dar yapraklılar ise sapları sayılarak değerlendirilmiş ve sürvey formlarına işlenmiştir.

Bulunan yabancı otların yoğunlukları (bitki $\mathrm{m}^{-2}$ ) ve rastlama sıklıkları (RS, \%) Odum (1971) ve Güncan (2014)'a ait aşağıdaki formüller kullanılarak hesaplanmıştır.

$$
\begin{aligned}
& Y=\frac{b}{m} \\
& R S=\frac{n}{m} \times 100
\end{aligned}
$$

Burada RS, rastlama sıklığı (\%); Y, yoğunluk (adet $\mathrm{m}^{-2}$ ); m, örnekleme yapılan toplam buğday tarlası sayısı; $n$, türün bulunduğu buğday tarlası sayıs1; $b$, alınan örnekte toplam birey sayısıdır.

Yabancı otların türlerinin teşhisleri ve isimlendirilmesinde Uluğ ve ark. (1993), Baytop (1989), Davis (1965-1989), Bryson and DeFelice (2009), THD (2017) ve TUBIVES (2017)'den yararlanılmıştır.

\section{SONUÇLAR}

Diyarbakır ili buğday tarlalarında yapılan gözlemler sonucunda biri damarlı tohumsuz, 19'u monokotiledon, 87'si dikotiledon olmak üzere 26 familyaya ait toplam 107 yabancı ot türü tespit edilmiştir. Bu türlere ait rastlama sıklıkları ve yoğunlukları Çizelge 2'de verilmiştir. 
Çizelge 2. Diyarbakır ili buğday tarlalarında saptanan yabancı ot türleri, rastlama sıklıkları ve yoğunlukları

\begin{tabular}{|c|c|c|c|c|}
\hline Bilimsel adı & Yerel adı & Familya & $\mathrm{RS}^{*}$ & $\mathbf{Y} *$ \\
\hline Acroptilon repens (L.) DC. & Kekre & Asteraceae & 3 & 0.03 \\
\hline Adonis aestivalis L. & Kandamlası & Ranunculaceae & 7 & 0.31 \\
\hline Aegilops cylindria Host. & Sakalotu & Poaceae & 2 & 0.08 \\
\hline Agrostemma githago L. & Karamuk & Caryophyllaceae & 26 & 0.43 \\
\hline Agrostis stolonifera L. & Narin tavus otu & Poaceae & 2 & 0.08 \\
\hline Allium $\mathrm{sp.}$ & Yabani sarımsak & Liliaceae & 4 & 0.05 \\
\hline Alopecurus myosuroides Huds. & Tilkikuyruğu & Poaceae & 38 & 1.03 \\
\hline Ammi visnaga (L.) Lam. & Kürdan otu & Apiaceae & 2 & 0.08 \\
\hline Anagallis arvensis L. & Farekulağ1 & Primulaceae & 17 & 0.27 \\
\hline Anchusa azurea Miller. & İtalyan sığırdili & Boraginaceae & 4 & 0.05 \\
\hline Anthemis arvensis L. & Tarla köpek papatyası & Asteraceae & 44 & 1.29 \\
\hline Anthemis tinctoria L. & Boyacı papatyası & Asteraceae & 2 & 0.03 \\
\hline Aristolochia maurorum L. & Loğusa otu & Aristolochiaceae & 2 & 0.12 \\
\hline Asperula arvensis L. & Tarla yapışkan otu & Rubiaceae & 2 & 0.08 \\
\hline Astragalus sp. & Geven & Fabaceae & 2 & 0.08 \\
\hline Atriplex patula L. & Karapaz1 & Chenopodiaceae & 4 & 0.06 \\
\hline Avena fatua $\mathrm{L}$. & Yabani yulaf & Poaceae & 87 & 9.73 \\
\hline Avena sterilis $\mathrm{L}$. & Kisır yabani yulaf & Poaceae & 50 & 1.90 \\
\hline Bifora radians Bieb. & Kokar ot & Apiaceae & 20 & 0.35 \\
\hline $\begin{array}{l}\text { Boreava orientalis Jaub and } \\
\text { Spach. }\end{array}$ & Sar1 ot & Brassicaceae & 24 & 0.48 \\
\hline Bromus sterilis L. & Kisır brom & Poaceae & 3 & 0.14 \\
\hline Bromus tectorum $\mathrm{L}$. & Püsküllü çayır & Poaceae & 13 & 0.80 \\
\hline $\begin{array}{l}\text { Buglossoides arvense (L.) } \\
\text { Johnst. }\end{array}$ & Taşkesen otu & Boraginaceae & 12 & 0.55 \\
\hline Bunium paucifolium DC. & Yabani kimyon & Apiaceae & 2 & 0.08 \\
\hline Bupleurum rotundifolium L. & Tavşankulağı & Apiaceae & 2 & 0.08 \\
\hline $\begin{array}{l}\text { Capsella bursa-pastoris (L.) } \\
\text { Medik. }\end{array}$ & Çobançantası & Brassicaceae & 51 & 1.61 \\
\hline Cardaria draba (L.) Desv. & Yabani tere & Brassicaceae & 10 & 0.21 \\
\hline Carduus nutans L. & Diken & Asteraceae & 2 & 0.08 \\
\hline Carduus pycnocephalus L. & Saka dikeni & Asteraceae & 4 & 0.12 \\
\hline Caucalis platycarpos L. & Küçük pitrak & Apiaceae & 9 & 0.25 \\
\hline Centaurea depressa Bieb. & Yatık gökbaş & Asteraceae & 40 & 1.89 \\
\hline Centaurea solstitialis $\mathrm{L}$. & Güneş dikeni & Asteraceae & 10 & 0.21 \\
\hline Cephalaria syriaca (L.) Schrad. & Pelemir & Dipsaceae & 2 & 0.10 \\
\hline Cerastium dichotomum $\mathrm{L}$. & Boynuz otu & Caryophyllaceae & 11 & 0.21 \\
\hline Chondrilla juncea L. & Akhindiba & Asteraceae & 9 & 0.16 \\
\hline Cichorium intybus L. & Yabani hindiba & Asteraceae & 16 & 0.18 \\
\hline
\end{tabular}


Çizelge 2. Devamı

\begin{tabular}{|c|c|c|c|c|}
\hline Bilimsel adı & Yerel adı & Familya & $\mathbf{R S}^{*}$ & $\mathbf{Y}^{*}$ \\
\hline Cirsium arvense (L.) Scop. & Köygöçüren & Asteraceae & 58 & 2.45 \\
\hline $\begin{array}{l}\text { Consolida orientalis (Gay) } \\
\text { Schrid. }\end{array}$ & Hazeran & Ranunculaceae & 13 & 0.32 \\
\hline Convolvulus arvensis L. & Tarla sarmaşı̆̆g & Convolvulaceae & 4 & 0.22 \\
\hline Daucus carota $\mathrm{L}$. & Yabani havuç & Apiaceae & 7 & 0.23 \\
\hline Descurainia sophia (L.) Webb & Uzun süpürge otu & Brassicaceae & 5 & 0.13 \\
\hline Equisetum arvense L. & Atkuyruğu & Equisetaceae & 5 & 0.16 \\
\hline Erodium hoefftianum C.A.Mey & Dönbaba & Geraniaceae & 10 & 0.21 \\
\hline Euphorbia helioscopia L. & Güneş sütleğeni & Euphorbiaceae & 10 & 0.17 \\
\hline Fumaria officinalis L. & Şahtere & Papaveraceae & 32 & 1.04 \\
\hline Galium aparine L. & Dil kanatan & Rubiaceae & 62 & 5.94 \\
\hline Galium tricornutum Dandy. & Boynuzlu yoğurt otu & Rubiaceae & 23 & 0.59 \\
\hline Geranium dissectum L. & Turnagagası & Geraniaceae & 19 & 1.08 \\
\hline Geranium tuberosum L. & Yabani çam çiçeği & Geraniaceae & 13 & 0.38 \\
\hline Glycyrrhiza glabra L. & Meyan kökü & Fabaceae & 1 & 0.02 \\
\hline Hordeum sp. & Yabani arpa & Poaceae & 53 & 0.92 \\
\hline $\begin{array}{l}\text { Hypericum triquetrifolium } \\
\text { Turra. }\end{array}$ & Kantaron otu & Guttiferae & 2 & 0.06 \\
\hline Isatis tinctoria $\mathrm{L}$. & Yabani çivit otu & Brassicaceae & 22 & 0.36 \\
\hline Lactuca serriola L. & Yabani dikenli marul & Asteraceae & 33 & 0.66 \\
\hline Lamium amplexicaule L. & Ballıbaba & Lamiaceae & 8 & 0.18 \\
\hline Lathyrus sp. & Yabani mürdümük & Fabaceae & 6 & 0.08 \\
\hline Lens culinaris Medik & Kendi gelen mercimek & Fabaceae & 57 & 1.53 \\
\hline Lolium multiflorum Lam. & Delice & Poaceae & 12 & 0.23 \\
\hline Lolium perenne L. & İngiliz çimi & Poaceae & 33 & 0.69 \\
\hline Malva neglecta Wallr. & Ebegümeci & Malvaceae & 8 & 0.17 \\
\hline Malva sylvestris L. & Yabani ebegümeci & Malvaceae & 1 & 0.03 \\
\hline Matricaria chamomilla L. & Hakiki papatya & Asteraceae & 14 & 0.70 \\
\hline Medicago sativa $\mathrm{L}$. & Yabani yonca & Fabaceae & 1 & 0.02 \\
\hline Melilotus officinalis (L.) Desr. & Sarı taş yoncası & Fabaceae & 5 & 0.13 \\
\hline Myagrum perfoliatum L. & Gönül hardalı & Brassicaceae & 7 & 0.12 \\
\hline Neslia apiculata Fisch. & Trakya hardalı & Brassicaceae & 8 & 0.19 \\
\hline Neslia paniculata (L.) Devs. & Topluiğne hardalı & Brassicaceae & 7 & 0.23 \\
\hline Papaver rhoeas L. & Gelincik & Papaveraceae & 56 & 2.62 \\
\hline Phlaris bractystachys Link. & Kısa kuşyemi & Poaceae & 2 & 0.03 \\
\hline Phlaris paradoxa $\mathrm{L}$. & Yumuşak kuşyemi & Poaceae & 49 & 1.38 \\
\hline Phragmites communis Trin. & Kamış & Poaceae & 7 & 0.15 \\
\hline Pisum sativum L. & Bezelye & Fabaceae & 1 & 0.03 \\
\hline Plantago lanceolata $\mathrm{L}$. & Sinir otu & Plantaginaceae & 2 & 0.07 \\
\hline Pоа аппиа L. & Salkım otu & Poaceae & 2 & 0.04 \\
\hline
\end{tabular}


Çizelge 2. Devamı

\begin{tabular}{|c|c|c|c|c|}
\hline Bilimsel adı & Yerel adı & Familya & $\mathbf{R S}^{*}$ & $\mathbf{Y}^{*}$ \\
\hline Poa bulbosa L. & Yumrulu salkım otu & Poaceae & 2 & 0.03 \\
\hline Poa trivialis $\mathrm{L}$. & Çayır salkım otu & Poaceae & 42 & 0.93 \\
\hline Polygonum aviculare L. & Çobandeğneği & Polygonaceae & 6 & 0.08 \\
\hline Polygonum convolvulus L. & \begin{tabular}{|l|} 
Sarmaşık \\
çobandeğneği
\end{tabular} & Polygonaceae & 9 & 0.17 \\
\hline Ranunculus arvensis L. & Tarla düğün çiçeği & Ranunculaceae & 72 & 2.28 \\
\hline Raphanus raphanistrum L. & Yabani turp & Brassicaceae & 3 & 0.15 \\
\hline Reseda lutea $\mathrm{L}$. & Muhabbet çiçeği & Resedaceae & 2 & 0.07 \\
\hline Rumex crispus L. & Kivircik labada & Polygonaceae & 1 & 0.06 \\
\hline Salsola kali L. & Soda otu & Chenopodoceae & 9 & 0.20 \\
\hline Scandix pecten-veneris L. & Zühre tarağg & Apiaceae & 13 & 0.61 \\
\hline Secale cereale $\mathrm{L}$. & Çavdar & Poaceae & 13 & 0.21 \\
\hline $\begin{array}{l}\text { Senecio vernalis Waldst and } \\
\text { Kit. }\end{array}$ & İmam kavuğu & Asteraceae & 1 & 0.02 \\
\hline Senecio vulgaris $\mathrm{L}$. & Kanarya otu & Asteraceae & 6 & 0.11 \\
\hline Silene conoidea $\mathrm{L}$. & Yapışkan nakıl & Caryophyllaceae & 9 & 0.32 \\
\hline $\begin{array}{l}\text { Silene vulgaris (Moench) } \\
\text { Garcke. }\end{array}$ & Adi nakıl & Caryophyllaceae & 8 & 0.36 \\
\hline $\begin{array}{l}\text { Silybum marianum (L.) } \\
\text { Gaertner }\end{array}$ & Meryem dikeni & Asteraceae & 9 & 0.50 \\
\hline Sinapis arvensis L. & Yabani hardal & Brassicaceae & 78 & 8.83 \\
\hline Sisymbrium officinale (L.) Scop. & Bülbül otu & Brassicaceae & 8 & 0.19 \\
\hline Sonchus asper (L.) Hill. & Dikenli eşek marulu & Asteraceae & 2 & 0.05 \\
\hline Sonchus oleraceus L. & Adi eşek marulu & Asteraceae & 8 & 0.61 \\
\hline Sorghum halepense (L.) Pers. & Kanyaş & Poaceae & 3 & 0.10 \\
\hline Stellaria media (L.) Vill. & Serçe dili & Caryophyllaceae & 8 & 0.36 \\
\hline Taraxacum sp. & Karahindiba & Asteraceae & 2 & 0.08 \\
\hline Thlaspi arvense L. & Tarla akça çiçeği & Brassicaceae & 2 & 0.12 \\
\hline Tordylium syriacum L. & Suriye geyik otu & Apiaceae & 2 & 0.07 \\
\hline Tragopogon latifolius Boiss. & Yemlik & Asteraceae & 18 & 0.29 \\
\hline Trifolium sp. & Üçgül & Fabaceae & 6 & 0.23 \\
\hline Turgenia latifolia (L.) Hoffm. & Pitrak & Apiaceae & 54 & 1.42 \\
\hline Vaccaria pyramidata Medik & Arap baklas1 & Caryophyllaceae & 26 & 1.07 \\
\hline Veronica hederifolia L. & Adi yavşan otu & Scrophulariaceae & 11 & 0.24 \\
\hline Vicia narbonensis L. & Kaba tüylü fiğ & Fabaceae & 1 & 0.07 \\
\hline Vicia sativa $\mathrm{L}$. & Adi fiğ & Fabaceae & 9 & 0.52 \\
\hline
\end{tabular}

Belirlenen tür sayılarının familya dağılımına bakıldığında, ilk sırayı 19 türle Asteraceae almıştır. Bunu 18 türle Poaceae takip etmiştir (Şekil 1). 


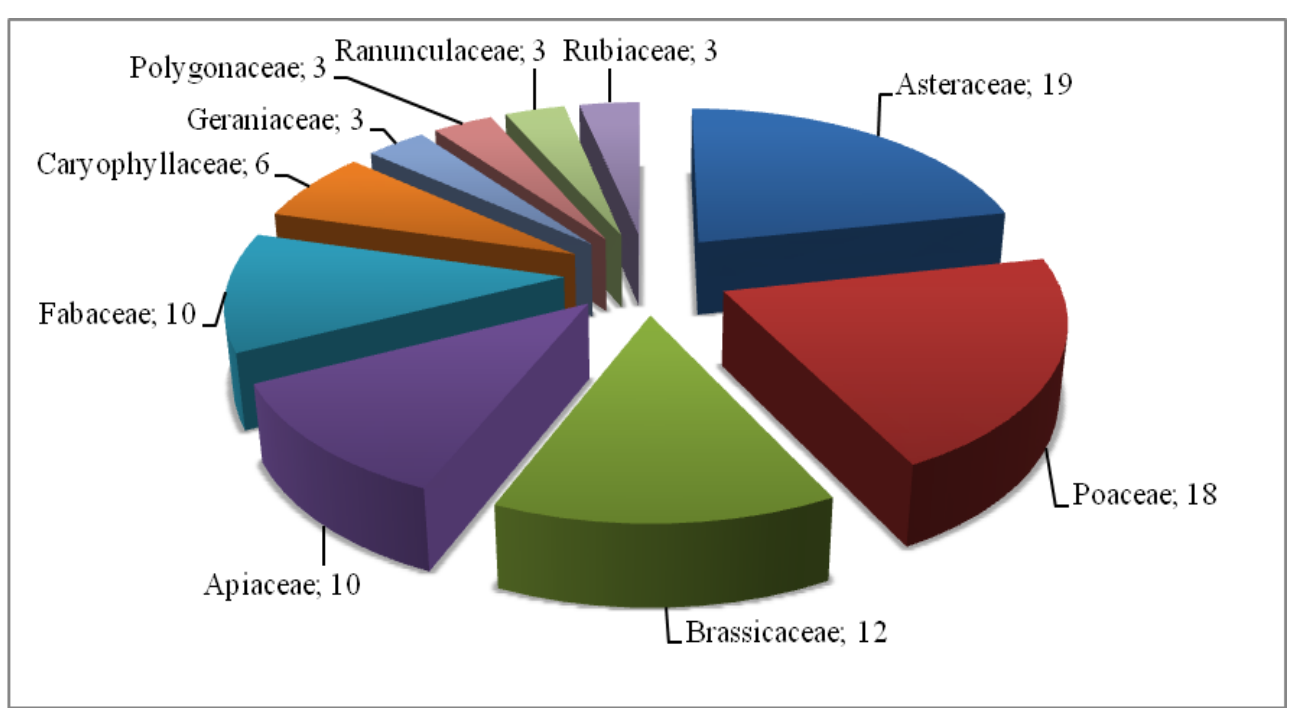

Şekil 1. Sürveylerde belirlenen yabanc1 ot tür sayılarının familyalara göre dağılımı.

Diyarbakır ili buğday ekim alanlarında yapılan sürveyler sonucu rastlama sıklı̆g $\% 50$ 'den fazla olan türlerin sirasıyla Avena fatua (\%87), Sinapis arvensis (\%78), Ranunculus arvensis (\%72), Galium aparine (\%62), Cirsium arvense (\%58), Lens culinaris (\%57), Papaver rhoeas (\%56), Turgenia latifolia (\%54), Hordeum sp. (\%53) ve Capsella bursa-pastoris (\%51) olduğu görülmüştür. Sürvey yürütülen tarlalarda tespit edilen yabancı otlar yoğunluklarına göre değerlendirildiğinde ise Avena fatua $\left(9.73\right.$ bitki m$\left.^{-2}\right)$, Sinapis arvensis $\left(8.83\right.$ bitki m$\left.^{-2}\right)$, Galium aparine $(5.94$ bitki $\left.\mathrm{m}^{-2}\right)$, Papaver rhoeas $\left(2.62\right.$ bitki $\left.\mathrm{m}^{-2}\right)$, Cirsium arvense $\left(2.45\right.$ bitki $\left.\mathrm{m}^{-2}\right)$, Ranunculus arvensis $\left(2.28\right.$ bitki $\left.\mathrm{m}^{-2}\right)$, Avena sterilis $\left(1.90\right.$ bitki $\left.\mathrm{m}^{-2}\right)$, Centaurea

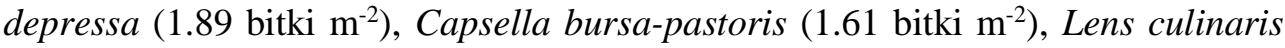

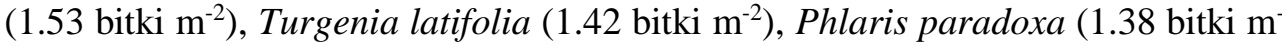
$\left.{ }^{2}\right)$, Anthemis arvensis $\left(1.29\right.$ bitki $\left.\mathrm{m}^{-2}\right)$, Geranium dissectum $\left(1.08\right.$ bitki $\left.\mathrm{m}^{-2}\right)$, Vaccaria

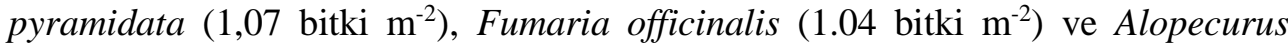
myosuroides $\left(1.03\right.$ bitki $\left.\mathrm{m}^{-2}\right)$ metrekarede birden fazla olduğu belirlenmiştir (Çizelge 2).

Farklı ilçelerdeki buğday tarlalarında yapılan sürveyler dikkate alındığında, baskın türleri büyük oranda aynı yabancı ot türlerinin oluşturduğu görülmektedir. Örneğin A. fatua rastlama sıklı̆g 1 ve yoğunluğu en fazla olan tür olmuştur. Bununla birlikte yabancı otların yaygınlık ve yoğunluklarında kısmen farklılıklar söz konusudur. Örneğin $R$. arvensis'in dağılımı fazla iken, G. aparine birim alanda daha fazla bulunmuştur.

\section{TARTIŞMA VE KANI}

Bitkisel üretimi sınırlandıran en önemli faktörlerden biri olan yabancı otlar ile mücadele edilmesi gerekmektedir (Güncan 2014, Mennan ve Iş1k 1993, Tepe 2014). 
Tarım alanlarında bulunan yabancı ot türlerinin bilinmesi, bunların biyolojisi, ekonomik zarar seviyeleri ve rekabet yeteneklerinin belirlenmesi ve en nihayetinde entegre kontrol yöntemlerinin geliştirilmesi için önemlidir (Pala ve Mennan 2014). Diyarbakır ili buğday tarlalarında görülen yabancı otların yaygınlı ve yoğunluklarının belirlenmesi amacıyla yürütülen bu çalışma sonucunda tür sayısı bakımından en çok Asteraceae (19 tür) familyasının, ikinci sırada ise Poaceae (18 tür) familyasının en fazla tür içerdiği görülmüştür. Söz konusu bitki familyalarının ülkemizde en fazla tür içeren familyalardan ikisi olması nedeniyle en fazla yabancı ot türünün bu iki familyadan çıkmış olması doğal bir sonuçtur. Daha önce yapılan birçok sürvey çalışmasında da bu iki familyanın en fazla tür içeren familyalar arasında yer aldığı sıklıkla görülmektedir (Boz ve ark. 2000, Gökalp ve Üremiş 2015, Mennan ve Uygur 1994, Özaslan 2011, Sirma ve Kadığlu 2010, Tursun 2002).

Yapılan sürveyler sonucunda buğday tarlalarında Avena fatua, Sinapis arvensis, Ranunculus arvensis, Galium aparine, Circium arvense, Lens culinaris, Papaver rhoeas ve Turgenia latifolia gibi kışlık yabanc1 ot türlerinin baskın olduğu görülmektedir. Diyarbakır ilinin karasal iklim kuşağında yer alması ve Akdeniz ikliminden etkilenmesi, oldukça sıcak ve kurak bir iklime sahip olması nedeniyle bu ekolojik koşullara iyi uyum sağlamış olan bu türlerin buğday tarlalarında sorun olması beklenen bir durumdur. Diyarbakır ili buğday tarlalarında 1966 ve 1992 yıllarında yürütülen çalışmalarda dil kanatan (19.29 ve 2.3 adet $\left.\mathrm{m}^{-2}\right)$ ve tarla düğün çiçeği $\left(4.38\right.$ ve 1.6 adet $\mathrm{m}^{-2}$ ) gibi yabanc1 ot türlerinin sorun olduğu belirlenmiştir (Uludağ ve Katkat 1993, Zel 1974). Son yıllarda Diyarbakır buğday üretim alanlarında kısır yabani yulafın yoğun olduğu (Sizer ve Tepe 2016), buğdaymercimek münavebe sisteminde yabani hardal, tarla düğün çiçeği, dil kanatan, gelincik ve pıtrağın çalışma yapılan alanda baskın yabancı ot türleri olduğu belirtilmiştir (Gürsoy et al. 2014).

Boz (2000) tarafından Aydın ili buğday alanlarında en sık rastlanan yabancı ot türü olarak tespit edilen papatya (\%63 ve 1.76 adet $\mathrm{m}^{-2}$ ) bu çalışmada daha düşük sıklıkta (\%14 ve 0.70 adet $\mathrm{m}^{-2}$ ) bulunmuştur. Boz ve ark. (2000), Denizli'de buğdayda yaptıkları çalışmada çobandeğneğini (\%57) en çok rastlanan yabancı ot türü olarak bildirmiş, ancak yaptığımız çalışmada, bu tür, düşük sıklıkta (\%6) görülmüştür. Kaya ve Zengin (2000), Erzurum'da buğdayda tarla sarmaşı̆̆ını (\%75) en sık rastlanan tür olarak bildirmiş, ancak bu yabanc1 ot ilimizde az sıklıkta (\%4) saptanmıştır. Sırma ve Kadığlu (2010), Erzincan'da buğdayda gökbaşın en sık (\%65 ve 1.72 adet $\left.\mathrm{m}^{-2}\right)$ ve pitrağın (\%59 ve 2.36 adet $\left.\mathrm{m}^{-2}\right)$ en yoğun tür olduğunu bildirmiştir. Her iki tür sirasıyla $\% 40$ ve 1.89 adet m$^{-2}$ ile $\% 20$ ve 0.35 adet $\mathrm{m}^{-2}$ olarak ilimizden daha düşük değerde bulunmuştur. Tursun (2002), Kahramanmaraş buğday

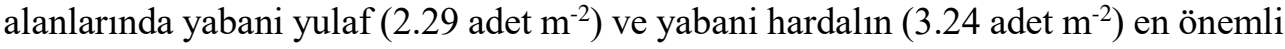
yabanc1 otlar olduğunu ve bunlara \%50'nin üstünde rastlandığını bildirmiş ve bu durum ilimizde elde edilen sonuçlarla örtüşmüştür. Gökalp ve Üremiş (2015), Mardin'in Kızıltepe ilçesinde buğday ekim alanlarında yabani yulaf $\left(1.90\right.$ adet $\left.^{-2}\right)$, yabani hardal $\left(1.10\right.$ adet $\left.\mathrm{m}^{-2}\right)$ ve dil kanatanın (1.99 adet $\left.\mathrm{m}^{-2}\right)$ yoğun olduğu yönündeki saptamaları yaptığımız çalışma ile paralellik göstermiştir. Bükün (2004), 
Şanlıurfa'da en yoğun türlerin yabani yulaf $\left(25.16\right.$ adet $\left.\mathrm{m}^{-2}\right)$, dil kanatan (15.3 adet $\mathrm{m}^{-2}$ ) ve yabani hardal $\left(7.48\right.$ adet $\left.\mathrm{m}^{-2}\right)$ olduğunu belirlemiş ve bu sıralama farklı olsa da bizim çalışmamızdaki en önemli üç tür ile benzerlik göstermiştir. Özaslan (2011) Diyarbakır buğday alanlarında yapılan sürvey çalışmalarında, rastlama sıklığı \%50'den fazla olan yabancı otların yabani yulaf, yabani hardal, dil kanatan olduğunu bildirmiş ve yapılan çalışma ile bu durumun devam ettiği görülmüştür. Buna benzer olarak elde edilen sonuçlar başka bölgelerde buğday alanlarında yapılan bazı sonuçlarla da benzerlik göstermektedir (Boz ve ark. 2000, Gökalp ve Üremiş 2015, Güncan 2014, Kadioğlu 1989, Kaya ve Zengin 2000, Keshavarzi 2015, Kitiş ve Boz 2003, Kordali ve Zengin 2011, Kraehmer 2016, Özaslan 2011, Sırma ve Kadığlu 2010, Sizer ve Tepe 2016, Tursun 2002, Uygur ve ark. 1993). İklim farklar1, yetiştiricilik teknikleri ve özellikle uygulanan yabancı ot kontrol yöntemleri tarım alanlarındaki yabancı ot kompozisyonunu değiştirebilmektedir.

Yabancı otların yoğunluk olarak en yüksek olduğu ilçe Sur olarak tespit edilmiştir. Diyarbakır ilinde buğday üretiminin en yoğun yapıldığı bölge Sur ilçesidir (665.506 da). İlçede genellikle kuru tarım yapılmaktadır ve en karlı tarımsal faaliyet buğday üretimidir. Bitkisel üretim açısından fazla bir seçeneğe sahip olmayan ilçede çiftçilerin gerek üretim teknikleri açısından gerekse zirai mücadele açısından daha dikkatli davranmalarını gerektirmektedir. Yabancı otların yoğunluğunun düşük çıktığı Bismil ilçesinde ise en önemli faktörün sulama imkânlarından dolay1 buğdayda uygulanan münavebe olduğu anlaşılmaktadır. Tespit edilen yabancı ot türlerinin farklı ilçelerdeki dağılımına bakıldığında büyük bir değişikliğin olmadığı ve hemen hemen aynı türlerin yaygın ve yoğun olduğu görülmüştür. Bu sonuç, buğdayın tür ya da çeşidinin yabancı ot florası üzerinde çok belirgin bir etkisinin olmadığını göstermektedir.

Diyarbakır ili buğday alanlarında hem en sık rastlanan hem de en yoğun türün aynı zamanda ülkemiz buğday alanları için de sorun olan yabani yulaf olduğu bilinmektedir. Yürütülen bu çalışma, buğdayda yapılacak yabancı ot mücadele çalışmalarının temelini oluşturacak verileri içerdiği için oldukça önemlidir.

Türkiye'de Aegilops cylindrica, Alopecurus myosuroides, Avena sterilis, Bifora radians, Boreava orientalis, Bromus spp., Circium arvense, Galium aparine, Galium tricornutum, Lolium spp., Phlaris spp., Sinapis arvensis, Tripleurospermum maritimum, Vicia spp. sorun olan önemli yabancı otlardır (Dikici and Dündar 2006, Mennan and Zandstra 2003, Mennan et al. 2003, Türkseven et al. 2009). Diyarbakır ili buğday tarlalarında tespit edilen yabancı otların, Türkiye'de buğday yetiştirilen diğer iller dikkate alındığında, türler yönünden benzerlik gösterdiği görülmektedir. Ancak yabancı otların yoğunluğu, rastlama sıklığı ve kaplama alanlarında bölgeden bölgeye, yıldan yıla farklılık saptanmıştır.

Avrupa'da Alopecurus myosuroides Huds., Alopecurus geniculatus L., Ambrosia artemisiifolia L., Anthemis spp., Apera spca-venti (L.) P. Beauv., Avena fatua L., Avena sterilis L., Chenopodium album L., Circium arvense (L.) Scop., Convolvulus arvensis L., Elytrigia repens (L.) Nevski, Galeopsis tetrahit L., Galium aparine L., 
Lolium multiflorum Lam., Lolium rigidum Gaudin, Lolium perenne L., Matricaria spp., Papaver rhoeas L., Poa annua L., Stellaria media (L.) Vill., Thalaspi arvense L., Tripleurosporum maritimum (L.) W.D.J. Koch, Veronica spp., Viola arvensis Murray (Kraehmer and Stübler 2012, Moss et al. 2005, Radivojevic et al. 2006, Vanaga 2003); Rusya ve Kazakistan'da Alopecurus spp., Avena fatua L., Seteria viridis, Chenopodium album L., Cirsium arvense, Convolvulus arvensis, Descurainia sophia, Fallopia convolvulus, Galium aparine, Sonchus arvensis (Luneva 2009, Spaar and Schuhmann 2000); Çin'de Alopecurus aequalis Sobol., Alopecurus japonicus Steud., Avena fatua L., Bromus japonicus Thunb., Descurainia sophia (L.) Schur., Fallopia convolvulus, Galium aparine L., Poa annua L., Polygonum spp. (He et al. 2010, Hun et al. 2008, Wang et al. 2000, Zhang et al. 1998); Pakistan, Hindistan ve Nepal'de Acroptilon repens (L.) DC., Alopecurus nepalensis Trin., Alopecurus aequalis, Alopecurus myosuroides, Avena fatua L., Avena ludoviciana, Avena sterilis L., Chenopodium album L., Galium aparine, Melilotus indicus (L.) All., Melilotus albus Medik., Cynodon dactylon (L.) Pers., Phlaris minor, Polygonum plebejum R. (Ahmad and Shaikh 2003, Gupta et al. 2008, Ranjit and Suvanketnikom 2003, Siddiqui et al. 2010, Singh et al. 1995); İran'da Avena fatua L., Avena ludoviciana, Avena sterilis L., Caucalis spp., Scandix spp., Descurainia sophia, Eremopyrum bonaepartis (Spreng.) Nevski., Hordeum murimum L., Hordeum vulgare, Galium aparine, Phlaris minor, Secale cereale L., Xanthium spp. sorun olan önemli yabanc1 otlardır (Baghestani et al. 2006, Hassannejad and Ghafarbi 2013). Yabanc1 ot tür ve yoğunluğu yönünden diğer ülkeler ile mukayese edildiğinde yabancı ot türleri, yoğunluğu daha az benzer bulunmuştur. $\mathrm{Bu}$ farklılığın ortaya çıkmasında, ülke iklimi, toprak yapısı, rakımı, bitki çeşidi, allelopatik etki ve ekim alanın büyüklügü gibi çeşitli faktörler rol oynamıştır.

Diyarbakır ili buğday tarlalarında yabancı otların dağılımı incelendiğinde yabancı otlarla yeterli mücadele edilmediği görülmektedir. Bu alanlarda yabanc1 ot sorununun giderek artması muhtemeldir. Bu yabanc1 otlardan Avena spp., Sinapis arvensis, Ranunculus arvensis ve Galium aparine ciddi verim kayılarına neden olacaktır. İldeki buğday tarlalarında genellikle kimyasal kullanılarak yabancı ot mücadelesi yapıldığı, kısmen de kültürel önlemler uygulandığı bilinmektedir. Elde edilen sonuçlar, alınan tedbirlerin yeterli olmadığını, daha etkili uygulamaların yapılması gerektiğini ortaya koymaktadır. Bu uygulamalardan bazıları; sertifikalı tohumluk kullanımı, toleranslı çeşit geliştirilmesi, ekim öncesi pullukla derin sürüm, sık ekim, geç ekim olabilir. Diğer taraftan herbisit ile mücadelenin buğdayın kardeşlenme döneminde yabancı otun 2-6 yapraklı olduğu dönemde, uygun iklim ve toprak şartlarında, kalibrasyonu iyi yapılmış pülverizatör ile yapılması, erken ve geç uygulamalardan kaçınılması gerekmektedir. Son yıllarda ilimizde yabancı otlarda herbisitlere dayanıklılık problemi arttı̆̆ından dolayı (Sizer ve Tepe 2016) üründe münavebe yapılması, herbisitte rotasyona gidilmesi yabanc1 ot popülasyonunun düşürülmesi için dikkat edilmesi gereken önemli hususlardandır. Yabancı otlar 
konusunda buğday üreticilerine yönelik farkındalık etkinliklerinin yapılması aciliyet arz etmektedir.

Bu çalışma; Diyarbakır'da kışlık buğday üretim alanlarında belirlenen yabancı otların yaygınlık ve yoğunlukları dikkate alındığında mevcut mücadele yöntemlerinin yetersiz kaldığını ve alternatif kontrol yöntemlerinin geliştirilmesine ihtiyaç olduğunu göstermiştir.

\section{KAYNAKLAR}

AHDB 2017. Cereals and Oilseeds, Agriculture and Horticulture Department Board. https://cereals.ahdb.org.uk/ (Erişim tarihi: 01.06.2017).

Ahmad R. and Shaikh A.S. 2003. Common weeds of wheat and their control. Pakistan Journal of Water Resources, 7, 73-6

Baghestani M.A., Zand E. and Soufzadeh S. 2006. Iranian winter wheat's (Triticum aestivum L.) interference with weeds: I. Grain yield and competitive index. Pakistan Journal of Weed Science Research, 12, 119-29.

Baytop A. 1989. Türkiye'nin tıbbi ve zehirli bitkileri. İstanbul Üniversitesi Yayın No: 3560 Gençlik Matbaası, İstanbul, $290 \mathrm{~s}$.

Boz Ö. 2000. Aydın ili buğday ekim alanlarında bulunan yabancı otlar ile rastlama sıklıkları ve yoğunluklarının saptanması. Türkiye Herboloji Dergisi, 3 (2), 1-11.

Boz Ö., Doğan, M.N. ve Dura S. 2000. Denizli ili buğday ekim alanlarındaki yabancı otların yaygınlık ve yoğunluklarının saptanması. Türkiye Herboloji Dergisi, 3 (1), 37-52.

Bryson C.T. and DeFelice M.S. 2009. Weeds of South. University of Georgia Press, Athens and London, 30602, 468p.

Bükün B. 2004. Critical periods for weed control in cotton in Turkey. Weed Research, 44(5), 404-412.

Davis P.H. 1965-1989. Flora of Turkey and East Aegean Islands. Edinburg Univ. Press., Vol. 1-11, Edinburgh, 468p.

Dikici H. and Dündar G.D. 2006. Wheat-weed competition for nutrients in Kahramanmaras, Turkey. Pakistan Journal of Biological Sciences, 9, 341-4.

FAO 2017. Statistical data of FAOSTAT. http://www.fao.org/faostat/en/\#home (Erişim tarihi: 02.06.2017).

Gökalp Ö. ve Üremiş İ. 2015. Mardin buğday ekim alanlarında bulunan yabancı ot türlerinin, yaygınlıklarının ve yoğunluklarının belirlenmesi. Mustafa Kemal Üniversitesi Ziraat Fakültesi Dergisi, 20 (1), 13-22.

Gupta A., Joshi S.P. and Manhas R.K. 2008. Multivariate analysis of diversity and composition of weed communities of wheat fields in Doon Valley, India. Tropical Ecology, 49, 103-12.

Güncan A. 2014. Yabancı ot mücadelesi. Selçuk Üniversitesi Yayınevi, Konya, 309 s. 
Gürsoy S., Özaslan C., Urğun M., Kolay B. and Koç M. 2014. The effect of sowing time, tillage system and herbicides on weed species density, weed biomass and yield of lentil within a lentil-wheat sequence. Agriculture \& Foresty, 60 (3), 73-85.

Hassannejad S. and Ghafarbi S.P. 2013. Weed flora survey of Tabriz wheat (Triticum aestivum L.) fields. Journal of Biodiversity and Environmental Sciences, 3, 118-32.

He Z., Xia X. and Bonjean A.P.A. 2010. Wheat improvement in China. In: Cereals in China (He Z. \& Bonjean A.P.A., eds). CIMMYT, Mexico, D.F.

Hun Z., Chai T. and Su Z. 2008. Investigation of gramineae weeds in wheat fields in Xingtai of Hebei province. Journal of Hebei Agricultural Sciences, 12, 47-8.

Kadıoğlu İ. 1989. Çukurova Bölgesi buğday ekiliş alanlarında görülen yabani yulaf (Avena spp.) türleri, gelişme biyolojileri, buğday ile karşılıklı etkileşimleri ve kontrol olanakları üzerinde araştırmalar. Tarım ve Köyişleri Bakanlığı Araştırma Yayınları Serisi, Yayın No: 66, Ankara, $128 \mathrm{~s}$.

Kaya Y. ve Zengin H. 2000. Pasinler Ovasındaki buğday tarlalarında sorun oluşturan yabancı otlarla, rastlama sıklıkları, hayat formları ve fitocoğrafik bölgelerinin belirlenmesi. Türkiye Herboloji Dergisi, 3 (1), 17-26.

Keshavarzi K. 2015. Distribution map of weeds in wheat dry land farms by geographical information system application (case study: Kohgiluyeh-va-Boyerahmad Province, İran). Agricultural Communications, 3 (4), 16-22.

Kitiş Y.E. ve Boz Ö. 2003. Isparta ili buğday ekim alanlarındaki yabancı otların yaygınlık ve yoğunluklarının saptanması. Türkiye Herboloji Dergisi, 6 (1), 16-38.

Kordali Ş. ve Zengin H. 2011. Bayburt yöresinde arpa ekim alanlarında görülen yabancı otlar, yoğunlukları, yaygınlıkları ve topluluk oluşturma durumları üzerinde çalışmalar. Atatürk Üniversitesi Ziraat Fakültesi Dergisi, 42 (2), 117-131.

Kraehmer H. and Stübler H. 2012. Technical demands and political restrictions for weedcontrol. Julius-Kühn-Archiv, 434, 15-19.

Kraehmer H. 2016. Atlas of weed mapping. Wiley and Sons. Ltd., 472 p.

Luneva N.N. 2009. Agroatlas: 2003-2009 Project 'Interactive Agricultural Ecological Atlas of Russia and Neighboring Countries. Economic Plants and Their Diseases, Pests and Weeds'. Available at: www.agroatlas.ru/ (Erişim tarihi: 08.05.2017).

Mennan H. ve Işık D. 1993. Buğday tohumluğunda bulunan yabancı ot tohumlarının yoğunlukları ve bitkiye dönüşüm oranlarının saptanması. Türkiye Herboloji Dergisi, $6(1), 8-15$.

Mennan H. ve Uygur F. N. 1994. Samsun ili buğday ekim alanlarında görülen yabancı otların saptanması. OMÜ Ziraat Fakültesi Dergisi, 9 (2), 25-35.

Mennan H., Bozoglu M. and Isik D. 2003. Economic thresholds of Avena spp., and Alopecurus myosuroides in winter wheat fields. Pakistan Journal of Botany, 35, 147 54.

Mennan H. and Zandstr B.H. 2003. Weed floras changes in arable crops in Turkey. North Central Weed Science Society Proceedings, 58, 72. 
Moss S., Anderson-Taylor G., Beech P.A. and Cranwell S.D. 2005. The current status of herbicide-resistant grass and broadleaved weeds of arable crops in Great Britain. In: Proceedings of the BCPC International Congress, Glasgow, pp. 139-44.

Odum E.P. 1971. Fundamentals of ecology. W. B. Saunders Company, Philadelphia, London, Toronto, 574p.

Özaslan C. 2011. Diyarbakır ili buğday ve pamuk ekim alanlarında sorun olan yabancı otlar ile üzerindeki fungal etmenlerin tespiti ve bio-etkinlik potansiyellerinin araştırılması. Doktora tezi, Selçuk Üniversitesi, Fen Bilimleri Enstitüsü, Konya, 218 s.

Özer Z., Kadıŏlu İ., Önen H. ve Tursun N. 1998. Herboloji (Yabancı ot bilimi), 2. Bask1. Gaziosmanpaşa Üniversitesi, Ziraat Fakültesi Yayınları No: 20, Kitaplar Serisi No: $10,403 \mathrm{~s}$, Tokat.

Pala F. ve Mennan H. 2014. Güneydoğu Anadolu Bölgesi pamuk alanlarında bulunan horoz ibiği (Amaranthus spp.) türlerinin, yaygınlıklarının ve yoğunluklarının belirlenmesi. Mustafa Kemal Üniversitesi Ziraat Fakültesi Dergisi, 21 (2),139-148.

Radivojevic L., Stankovic-Kalecic R., Pavlovic D. and Marisavljevic D. 2006. Eficacy of several herbicides in controlling weeds in wheat. Journal of Plant Diseases and Protection XX, 787-93.

Ranjit J.D. and Suwanketnikom R. 2003. Response of weeds and wheat yield to tillage and weed management. Kasetsart Journal (Natural Science), 37, 389-400.

Shahzad M., Farook M. and Hussain M. 2016. Weed spectrum in different wheat-based cropping systems under conservation and conventional tillage practices in Punjab, Pakistan. Soil and Tillage Research, 163, 71-79.

Sırma M. ve Kadığlu İ. 2010. Erzincan Otlukbeli ilçesi buğday alanlarında saptanan önemli yabancı ot türleri, rastlanma sıklıkları ve yoğunlukları. GOÜ Ziraat Fakültesi Dergisi, 27 (1), 27-34.

Siddiqui I., Bajwa R., Huma Z.E. and Javaid A. 2010. Effect of six problematic weeds on growth and yield of wheat. Pakistan Journal of Botany, 42, 2461-71.

Singh S., Malik R.K., Balyan R.S. and Singh S. 1995. Distribution of weed flora of wheat in Haryana. Indian Journal of Weed Science, 27, 114-21.

Sizer V. ve Tepe I. 2016. Diyarbakır'da buğday alanlarında bulunan kısır yabani yulaf (Avena sterilis L.) biyotiplerinin clodinafop-propargyl ve mesosulfuronmethyl+iodosulfuron-methyl-sodium'a karşı duyarlıklarının belirlenmesi. Turkish Journal of Weed Science, 19 (2), 10-19.

Spaar D. and Schuhmann P. 2000. Natürliche Grundlagen der Pflanzenproduktion in den Ländern der Gemeinschaf Unabhängiger Staaten und des Baltikums, Agrimedia.

Tepe I. 2014. Yabancı otlarla mücadele. Sidas Medya Ziraat Yayın No:031, İzmir, 292 s.

THD 2017. Yabanc1 Otlar, Türkiye Herboloji Derneği. http://www.turkiyeherboloji.org.tr/ (Erişim tarihi: 19.05.2017).

TUBIVES 2017. Türkiye Bitkileri Veri Servisi. http://www.tubives.com/ (Erişim tarihi: 21.05.2017). 
Turk M.A. and Tawaha A.M. 2003. Weed control in cereals in Jordan. Crop Protection, 22, 239-246.

Tursun N. 2002. Kahramanmaraş ili ve ilçelerinde buğday ekim alanlarında sorun olan yabancı otların belirlenmesi. Türkiye Herboloji Dergisi, 5 (1), 1-11.

TÜIKK 2017. Bitkisel Üretim İstatistikleri, Türkiye İstatistik Kurumu. https://biruni.tuik.gov.tr/bitkiselapp/bitkisel.zul (Erişim tarihi: 17.05.2017).

Türkseven S., Demirci M., Uludag A. and Nemli Y. 2009. An expanding problem: Bromus spp. Paper presented at 2nd International Conference, Novel and sustainable weed management in arid and semi-arid agro-ecosystems, Santorini.

Uludağ A. ve Katkat M. 1993. Güneydoğu Anadolu Bölgesinde meyve fidanlıklarında bulunan yabancı otlar ve yoğunluklarının belirlenmesi üzerine çalışmalar. Türkiye I. Herboloji Kongresi, 3-5 Şubat, Adana, 175-184 s.

Uludağ A. 1997. Weed infestation level changes in cereal in Diyarbakir, Turkey. $10^{\text {th }}$ EWRS Symposium, p.22, Poznan.

Uluğ E., Kadıoğlu İ. ve Üremiş İ. 1993. Türkiye'nin yabancı otları ve bazı özellikleri. Tarım ve Köyişleri Bakanlığı, Zirai Mücadele Araştırma Enstitüsü Müdürlüğü, Yayın No:78, 513 s. Adana.

Uygur S., Erkılıç A. ve Uygur F.N. 1993. Çukurova bölgesinde bazı yabancı ot türlerinin konukçuluk ettiği fungal etmenler ve bunların bulaşıklık oranlarının araştırılması. Türkiye I. Herboloji Kongresi, 3-5 Şubat, Adana, 405-413 s.

Vanaga I. 2003. Weed infestation and control in spring and winter cereals in central Latvia. In: Vagos: Research Papers, Kaunas: Lithuanian University of Agriculture 59, pp. 98-103.

Wang Y., Huang C., Chen T. and Sun B. 2000. Weed survey in wheat fields in north region of Heilongjiang province. Heilongjiang Agricultural Science, 2, 12-14

Zel N. 1974. Doğu ve Güneydoğu Anadolu Bölgeleri hububat tarlalarında mevcut yabancı ot çeşitleri üzerine sürvey çalışması. Zirai Mücadele Araştırma Yıllı̆̆ı, 8-80.

Zhang C., Hu X. and Qian Y. 1998. Weed survey in wheat fields in Jianghan plain. Plant Protection, 24, 14-16. 